\section{"Que me bese con los besos de su boca": problemas interpretativos del comienzo del Cantar de los cantares}

Recibido: 02/02/2019. Aceptado: 12/05/2019

\section{Resumen}

El libro bíblico del Cantar de los cantares es un poema nupcial escrito en forma 'dramática'. Esta breve descripción de su forma y su contenido ofrece, desde el comienzo, dos dificultades: la interpretación espiritual de un texto que, según la letra, se refiere al amor humano y la adjudicación de las palabras del texto a los personajes, pues el texto bíblico no nos indica quién está hablando en cada momento. Gregorio de Nisa, siguiendo los pasos de Orígenes, escribió una serie de homilías al Cantar de los cantares donde debe resolver dichos problemas. Su respuesta se ve determinada, además, por el contexto polémico representado por la figura de Eunomio de Cízico, obispo arriano de la segunda generación.

\section{"O that he would kiss me with the kisses of his mouth": Problems of interpretation at the beginning of the Canticle of Canticles}

\begin{abstract}
The biblical book, Canticle of Canticles, is a nuptial poem written in the form of a 'drama'. This brief description of its form and content brings two difficulties to our attention: the spiritual interpretation of a text, which taken literally, refers to human love and the attribution of the words of the text to the characters, since the biblical text does not inform us who is speaking at each moment. Gregory of Nyssa, following Origen, wrote a series of homilies on the Canticle of Canticles where he had to confront such problems. His answer is moreover settled by the polemical context represented by the figure of Eunomius of Cyzicus, an Arian bishop of the second generation.
\end{abstract}

\section{Palabras clave}

Cantar de los cantares exégesis patrística Orígenes

Gregorio de Nisa Eunomio de Cízico

\section{Keywords}

Canticle of Canticles Patristic exegesis Origen

Gregory of Nyssa Eunomius of Cyzicus 
Que me bese con los besos de su boca, porque tus pechos son mejores que el vino y la fragancia de tus perfumes supera todos los aromas.

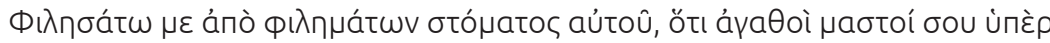

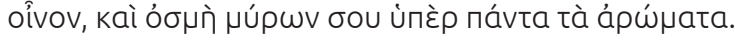

(Ct 1,2-3a)

El libro bíblico del Cantar de los cantares es un poema nupcial escrito en forma 'dramática'. La novia y el novio expresan el deseo de la unión amorosa. Los amigos del novio y de la novia también intervienen en el diálogo, propiciando ese deseo.

Dos problemas encontramos en la interpretación del texto bíblico. En primer lugar, el carácter nupcial del texto crea dificultad para hacer una lectura espiritual. Luego, su carácter dramático y el hecho de que el texto no presenta las didascalias ofrecen dificultad en el momento de la atribución de las expresiones a los distintos personajes.

Voy a estudiar en estas páginas la forma en que Gregorio de Nisa afronta estos dos problemas en la primera de sus Homilías sobre el Cantar de los Cantares. A esto añadiré una breve mención acerca del contexto polémico doctrinal que ofrece la última palabra en cuanto a la fundamentación del método interpretativo.

\section{Interpretación espiritual}

Veamos el primer problema, el de la interpretación espiritual. El carácter general del libro del Cantar, como canto nupcial, se expresa con imágenes y con un lenguaje propios del cortejo esponsal y de la unión carnal de los esposos. Para una interpretación espiritual se requiere una purificación de dicho lenguaje y de las imágenes de que se sirve. Y esta purificación se realiza por medio de un método exegético que justifica y al mismo tiempo permite el paso de la expresión material a la interpretación espiritual.

Encontramos la misma consideración en Placida (1997:33-34). La estudiosa considera que las adaptaciones de Gregorio se deben a su interés por algunos temas espirituales como el ascenso del alma a la perfección, el conocimiento de Dios y la unión mística con el Sumo Bien, que constituyen un esquema bien armado del conjunto de homilías. Ya lo había mostrado Franz Dünzl a partir de las distintas atribuciones (al esposo o a la esposa) de las expresiones de texto del Cantar de la diversa forma de afrontar los problemas de crítica textual, cfr. Dünzl (1993:100); y a partir de las variadas aplicaciones alegóricas de las imágenes, cfr. Dünzl (1993:102108). Puede verse una consideración más general acerca de la relación de las interpretaciones de Orígenes y Gregorio en Gargano (1981:240241) y Canévet (1983:128-131).

2. Cfr. Orígenes Tratado de los principios, IV 2 4, p. 840-843; véase también Orígenes In Leviticum, V 1, p. 333-334. Puede verse también Narvaja (2018:2228) donde presento diversas aplica-

ciones del triple esquema de la interpretación bíblica en el mismo Orígenes.

3. Cfr. Simonetti (1985:253). Véase también Simonetti (2018:141), donde describe lo que él denomina "defectus litterae" que determina la caída del interés por la interpretación literal.
A pesar de la simpatía que muestra Gregorio por el comentario de Orígenes al mismo libro bíblico, es muy libre en la recepción de su método de interpretación. ${ }^{1}$ Creo que el problema polémico del que hablaremos al final de este estudio, nos ofrecerá una posible razón para este distanciamiento del maestro alejandrino.

Es bien sabido que Orígenes hablaba de tres niveles de interpretación de la Escritura. Estos tres niveles correspondían a los tres elementos que componen al hombre: ${ }^{2}$ cuerpo - alma - espíritu. Dios que desea que se salven todos los hombres y se salve todo el hombre, dirige un mensaje de salvación a cada uno de sus componentes: la interpretación literal, es decir la historia, corresponde al cuerpo; la interpretación moral ofrece un mensaje dirigido al alma; y la interpretación alegórica, la superior y perfecta, presenta una enseñanza para la vida del espíritu.

Gregorio se desprende de este esquema exegético. Según Manlio Simonetti, ${ }^{3}$ en las Homilías sobre el Cantar de los cantares Gregorio elimina la interpretación literal y funde en uno solo los otros dos niveles: el amor de Cristo por la Iglesia y el amor del Logos por el alma. 
Es verdad que Gregorio rechaza una interpretación literal de este libro. Pero no rechaza el nivel corpóreo, la historia. Más bien la letra es un instrumento y medio para llegar a un conocimiento superior:

No dice que debemos salir de los movimientos de la carne o que debemos mortificar los miembros terrenos ni que debemos tener la boca pura de toda palabra pasional, sino que dispone el alma de manera que mira la pureza sirviéndose de aquellas expresiones que parecerían inconvenientes y, por medio de algunos discursos cargados de pasión, interpreta un pensamiento libre de toda mancha. (Gregorio de Nisa In canticum I, p. 798) ${ }^{4}$

El proceso es intelectual. No propone una destrucción del cuerpo ni una estigmatización de la unión carnal de los esposos (contra el maniqueísmo y contra toda forma de gnosticismo desencarnado). Propone, más bien, desligar la historia del texto bíblico de las imágenes que presenta para llegar a una interpretación que permita un conocimiento de la vida del espíritu, invisible e incorpóreo.

El Logos nos exhorta por medio de este libro [...] a que -aunque vivamos en la carne- no nos centremos en ella ni siquiera con el pensamiento, sino que miremos solamente al alma y consagremos cada significado de amor contenido en estas palabras, al bien que está por encima de todo intelecto, entendiéndolas de manera pura e inmaculada. (Gregorio de Nisa In canticum I, p. 800-802)

Sin eliminar la carnalidad en que vivimos, dirige la mirada desde la unión esponsal del hombre y la mujer a la unión de la Iglesia (del alma) con Cristo.

No vaya a suceder que uno, por medio de un razonamiento carnal [...] quede atado, junto con sus pensamientos, a esas pasiones animales e irracionales y refiera a ellas las palabras puras del esposo y de la esposa.(Gregorio de Nisa In canticum I, p. 772-774)

Por tanto, a partir de la unión del hombre y la mujer, propone una interpretación analógica de Cristo y la Iglesia.

La analogía no es de Gregorio. La establece Pablo en su carta a los Efesios, donde dice: "Maridos, amen a sus mujeres como Cristo amó a la iglesia" $(5,25)$; y más adelante en la misma carta: "El hombre dejará a su padre y a su madre para unirse a su mujer, y los dos serán una sola carne. Grande es este misterio que yo relaciono a la unión de Cristo y la iglesia" (5,31-32).

El mensaje espiritual del texto del Cantar -que es la enseñanza de Salomón para los perfectos- debe conducirnos a alcanzar lo perfecto: “Está claro que es necesario interpretar todo esto de manera que el significado del símbolo nos conduzca a las realidades mejores"(Gregorio de Nisa In canticum I, p.780). Y eso "mejor" es la unión esponsal del alma con Dios, pues: "El alma es adornada como una esposa y se prepara a la unión incorpórea, espiritual e inmaculada con Dios" (Gregorio de Nisa In canticum I, p. 774).

La búsqueda del bien más grande y espiritual no niega, no destruye ni rechaza los bienes inferiores y terrenos, -la corporeidad y la carnalidad, en este caso- pero exige, sin embargo, que alcemos la mirada desde ellos a lo alto y perfecto.
4. Todas las traducciones son mías. 
5. Cfr. Dünzl (1993-1:99-100). Es el único comentarista que hace eferencia a este problema y señala las diferencias de atribución (al esposo o a la esposa) que presentan Orígenes y Gregorio. Como puede verse, la falta de didascalias autoriza una interpretación u otra, basta que adquiera sentido en el conjunto de la exégesis.

6. Gregorio interpreta estas palabras como dichas por la esposa y explica que desea mamar de los pechos de los que mana el tesoro que está en el corazón del amado, cfr. Meis (1995:602) y las referencias de Laird (2018:174-176) a la obra de Galeno De placitis Hippocratis et Platonis acerca de la función epistémica del corazón.

7. Agradezco a la Prof. Francesca Cocchini que me haya permitido leer su Comentario al Cantar de los cantares aún sin publicar, en el que interpreta las palabras de este primer verso como pronunciado por el esposo.
Por otra parte, Dios se sirve de lo carnal para que podamos conocer lo espiritual y para despertar el deseo de lo más elevado. Lo material y corpóreo es el analogado necesario para el conocimiento de aquello de lo que no tenemos experiencia directa.

Sólo aquel Bien es auténticamente dulce, deseable y amable. Su gozo se vuelve un impulso cada vez más grande y un deseo mayor, porque justamente gracias a la participación en las cosas buenas nuestro deseo se desplaza cada vez más hacia adelante. (Gregorio de Nisa In canticum I, p.802)

Esta es la propuesta metodológica de Gregorio. Una vez que la ha expuesto, nos llevará a profundizar las palabras de Salomón.

De esta manera, después de haber purificado el corazón de cualquier actitud proclive a las realidades aparentes, entonces, por medio del Cantar de los cantares conduce nuestro pensamiento, místicamente, a la intimidad de los secretos divinos. (Gregorio de Nisa In canticum I, p. 786)

Vemos que, en cuanto a la intención, Gregorio no se ha separado de Orígenes. Sin embargo, su método se diferencia en un punto central.

Hay una unión más estrecha entre los dos niveles del método de Gregorio que la que observamos en Orígenes, evidentemente a causa de su matriz platónica. Para Gregorio la letra, la historia (esto es el cuerpo) es claramente el medio para alcanzar la unión espiritual. Sin la experiencia del goce carnal, pierde fuerza la imagen y se deslíe el mensaje espiritual.

\section{El problema del carácter dramático: los besos, los pechos y el perfume}

Veamos, en segundo lugar el problema que se nos presenta a raíz del carácter dramático del libro. Para Gregorio esto no es un problema, pero sí lo es para nosotros. El problema consiste en que el texto bíblico no contiene las didascalias, es decir no nos informa acerca de cuál es el personaje que está hablando. Esto queda en manos del intérprete. ${ }^{5}$

Gregorio, siguiendo a Orígenes, considera que las palabras de estos primeros versos son de la esposa.

Pero si tenemos en cuenta la imagen de los "pechos" que "son mejores que el vino", podríamos inclinarnos a pensar que son palabras del esposo. ${ }^{6}$ De hecho, algunos comentaristas actuales declaran que estas primeras palabras del libro son dichas por él. ${ }^{7}$

Otro problema de la falta de estas didascalias es que tampoco se dice a quién se dirigen las palabras. En los primeros versos del Cantar hay un cambio del destinatario de las palabras: "Que (él) me bese..." porque "tus pechos" y "tus perfumes".

Orígenes resuelve el problema diciendo que la primera frase la dirige la esposa al Padre del esposo y que en ese momento entra el esposo y, desde ese momento la esposa le dirige a él sus palabras. 
Para Gregorio el deseo de la esposa se manifiesta antes que aparezca el esposo. Habla consigo misma y expresa este anhelo.

[...] no es el esposo (como sucede habitualmente) el primero en ser poseído por el deseo, sino que es la novia quien se adelanta al esposo y manifiesta abiertamente su deseo, sin avergonzarse de él y lo expresa en cuanto anhela el gozo del beso del esposo. (Gregorio de Nisa In canticum I, p. 788)

En realidad, este comentario de Gregorio nos permite suponer que le pareció extraño que estas palabras estuvieran en labios de la esposa, pues "habitualmente" el deseo se despierta primero en el varón. La interpretación de las expresiones dejará en claro que está hablando la esposa.

Gregorio vuelve a servirse de la analogía para hacer una nueva distinción, en este caso entre los sentidos corpóreos y los sentidos espirituales. ${ }^{8}$ Los sentidos corpóreos se refieren a la letra del libro. Pero hemos visto que Gregorio nos proponía que todo lo corpóreo del libro debía servirnos para llevarnos al conocimiento de lo espiritual. Los sentidos espirituales, en consecuencia, se refieren a la experiencia del amor de Cristo/Logos por la Iglesia y el alma.

Aprendemos también otra cosa por medio de la filosofía contenida en este libro: la sensación que experimentamos es doble: una es la del cuerpo y la otra es más divina [...]. Las operaciones del alma poseen una cierta analogía con las funciones sensoriales del cuerpo. (Gregorio de Nisa In canticum I, p. 806)

Las operaciones del alma son comparables -tienen una cierta analogía- con los sentidos. Y el beso que pide la esposa corresponde al tacto espiritual.

Ahora bien, el beso se realiza por medio del sentido del tacto, ya que en el beso los labios se tocan. Pero existe también un contacto particular, el del alma: ella toca al Logos. Este beso se da por medio de un contacto difícil de definir, incorpóreo, intelectual, como dijo aquel que pronunció estas palabras: nuestras manos tocaron al Logos de la vida. (Gregorio de Nisa In canticum I, p. 806-808)

Como los labios se tocan en el beso, así Cristo toca a la Iglesia y el Logos toca el alma. ¿En qué consiste esta operación del besar de Dios? Había dicho Gregorio:

Si uno tiene sed, que venga a mí y beba, por este motivo el alma sedienta quiere acercar su boca a aquella boca que es fuente de la vida y dice: Que me bese con los besos de su boca. Y aquel del cual brota la vida y quiere que todos se salven, quiere que ninguno de los que se salvan quede sin ese beso, porque ese beso es purificador de todas las manchas. (Gregorio de Nisa In canticum I, p. 804)

No sólo es un beso puro, sino que es purificador. Y pasa desde esta interpretación del beso de los labios a la mención de los pechos, porque de esos labios se bebe el tesoro del corazón:

Pero el alma purificada -puesto que no la frena ningún labio carnal- mira el tesoro de las cosas buenas, al que damos el nombre de "corazón", y del cual proviene a los pechos el don de la leche divina que nutre al alma; ella mama la gracia según la proporción de la fe. (Gregorio de Nisa In canticuml, p. 804-806)

8. Puede verse al respecto Reyes Gacitúa (2006:368-369). 
9. He estudiado el problema de la teología eunomiana y su fundamentación en la filosofía del lenguaje en otros trabajos. Puede verse Narvaja (2003:28-59). Gargano (1981:240) presenta la hipótesis de que la controversia eunomiana haya influido en los derroteros exegéticos del Niseno. Vigorelli (2014:277) estudia el problema del lenguaje teológico, propio de la controversia con Eunomio, en la obra de Gregorio y en especial en sus homilías al Cantar. Su estudio se basa en el término oxźøıc introducido por Basilio y desarrollado por Gregorio. La mención de la problemática de Euniomio le sirve a la autora para contextualizar la problemática, pero no desarrolla el tema en paralelo. Dünzl (1993-2:295, 313) reconoce en algunos pasajes el contexto de la teología neoarriana de Eunomio aunque no lo lleve a una mayor profundización. Finalmente, podemos señalar la presentación del problema del nombre de Dios en relación con el conocimiento de su esencia como aparece en las homilías de Gregorio al Cantar, en Drecoll (2018: 182-186). Lamentablemente el autor no hace referencia a la doctrina de Eunomio combatida por Gregorio.

10. Placida (1997:40) muestra la contraparte de nuestra afirmación: "il Cristo incarnato costituisce il limite di conoscenza che l'anima può avere di Dio".
Y el tesoro de su corazón es su palabra, alimento gracioso para la vida divina en el hombre.

Porque las palabras del esposo son espíritu y vida y quien se une al esposo, se vuelve espíritu y quien se une a la vida, pasa de la muerte a la vida [...] por eso la esposa, que es el alma, desea acercarse a la fuente de la vida espiritual. (Gregorio de Nisa In canticum I, p. 804)

Por tanto, la espera ansiosa de los besos del esposo es expresión de la esperanza de que nunca le falte la enseñanza y la guía espirituales.

\section{Una conclusión polémica}

En el contexto de la polémica eunomiana, la Homilía I sobre el Cantar de los cantares concluye con una aplicación que se refiere a la raíz hermenéutica de la controversia acerca de la posibilidad del conocimiento de Dios. ${ }^{9}$

El problema de la interpretación del discurso carnal de los esposos del Cantar se resuelve por medio de una interpretación espiritual de los símbolos contenidos en la letra. Por analogía se llega a una interpretación que nos habla de la unión espiritual del alma con Dios.

Es importante subrayar que el método analógico es el que permite esa relación más estrecha entre el alma y el cuerpo de la que hemos hablado en el primer punto y que ha reaparecido en la doctrina de los dos sentidos y ahora en la doctrina acerca del conocimiento de Dios.

Según la formulación clásica, la analogía nos permite encontrar una semejanza entre Dios y la creatura, entre la vida del cuerpo y la vida del alma; pero por más grande que sea la semejanza, siempre será mayor la desemejanza. A esta formulación negativa debemos añadirle la necesidad del momento positivo.

La vida corpórea y el ser de la creatura, experimentables con los sentidos, son absolutamente necesarios para el conocimiento del ser invisible de Dios, para el conocimiento de los sentidos espirituales y la vida divina del alma. ${ }^{10}$

Aunque el resultado de esta interpretación es un conocimiento del obrar de Dios con el hombre, no llegamos, sin embargo, a un conocimiento de lo que es Dios en sí mismo (como pretendía Eunomio). En efecto, Eunomio sostenía que el conocimiento del nombre de Dios nos permite conocer perfectamente su esencia.

Gregorio va a concluir la homilía negando toda posibilidad de conocer qué es Dios según la esencia.

Con estas palabras, me parece que se hace alusión a [...] que no es posible circunscribir con exactitud por medio del significado de un nombre la naturaleza ilimitada, sino que toda potencia de los pensamientos, toda afirmación de las palabras y de los nombres, incluso si en apariencia poseen una grandeza propia de la naturaleza de Dios, no pueden, por su naturaleza, tocar aquello que existe verdaderamente [...] (Gregorio de Nisa In canticum I, p. 810-812) 
Subraya fundamentalmente el momento negativo propio de toda afirmación analógica.

[...] nuestra razón conjetura sobre aquel ser que es desconocido, siguiendo solamente algunas huellas, o como un pálido reflejo e imagina al incomprensible por medio de una analogía, basándose en lo que logra comprender. Todo nombre pensado [...] que nos permita conocer el perfume de la natura divina, no sirve para indicar por medio del significado de lo que estamos diciendo el mismo ungüento, sino que las palabras de nuestra teología indican sólo un mísero residuo de cuanto exhala del buen olor divino. (Gregorio de Nisa In canticum I, p. 812)

Partiendo de las cosas creadas la mente humana puede elevarse a aquel que las creó, aunque no es posible un conocimiento acabado. ${ }^{11}$

Esta es la enseñanza que sacamos de estas palabras, es decir, que el verdadero perfume de la naturaleza divina, sea lo que sea por su naturaleza, está por encima de todo nombre y de todo pensamiento, mientras que las maravillas que se admiran en el universo nos dan la materia de los nombres de la teología.

(Gregorio de Nisa In canticum I, p. 812)

El 'perfume' del Creador está presente en las cosas creadas. ${ }^{12}$ Sin embargo, la infinitud de Dios y el constante trabajo intelectual pone al hombre en un camino que no termina (recordemos cómo lo describe Gregorio en el concepto de epectasis $\left.{ }^{13}\right)$, buscando continuamente alcanzar a ese Dios cada vez más grande y cada vez más cercano. ${ }^{14}$

Por el contrario para Eunomio, el hombre comparte con Dios el lenguaje que -siguiendo la filosofía del Cratilo y de los Oráculos caldeos- es sacro porque es el lenguaje con el que Dios creó todas las cosas. ${ }^{15}$ Este lenguaje -grabado en el alma desde el nacimiento- permitiría, según el autor neoarriano, el conocimiento de la naturaleza de las cosas y del mismo Dios.

La consecuencia última de esta doctrina es la negación de la posibilidad de desarrollar una teología. Al conocer el nombre de Dios, el hombre es capaz de conocer acabadamente su misma esencia. Más que esto no es posible, más que esto no es necesario.

El proceso existencial del hombre que describe Gregorio desde su creaturalidad hasta llegar a la unión plena con Dios se opone a la idea prometeica de Eunomio de un hombre que se ha apoderado del poder verbal de su Creador.

En este contexto doctrinal resalta el método exegético de Gregorio.

Que me bese con los besos de su boca es el deseo de un alma que sabe que para su camino constante, intelectual y existencial ha de beber las palabras de la boca de su Esposo y ser guiada constantemente hasta llegar a la unión esponsal.
11. Refiriéndose al tema de la 'voz', Reyes Gacitúa (2011:185) señala la misma distancia (analógica) entre la 'voz del amado' y el 'amado cuya voz se siente'.

12. La imagen del 'perfume' tiene una larga tradición en el pensamiento antiguo, tanto pagano como cristiano. Véase el resumen que nos presenta Reyes Gacitúa (2007:207-208). Es interesante ver el estudio que la autora hace del uso de esta imagen en las homilías de Gregorio de Nisa (la "dinámica de los distintos personajes en torno al perfume"), aunque no trata particularmente el verso que da pie a nuestro estudio. Puede verse un estudio suyo anterior donde la imagen del 'perfume' aparece en el contexto del problema del conocimiento (2002:346). Una interpretación aún más cercana a la nuestra la encontramos en Placida (1997:35), para quien el perfume significa "la inconoscibilità e inaferrabilità della natura divina". Escribano-Alberca (1997:111) sitúa la interpretación de la imagen del 'perfume' y de la temática del 'aroma' en las homilías al Cantar de Gregorio en el contexto de transmisión de la experiencia religiosa y del mensaje del Cristo; y lo desarrolla más adelante en el apartado en el que trata de la analogía (1997:113). Sobre el tema del perfume como clave de interpretación de la teología mística a partir de Ct 1,3 puede verse la obra de mayor envergadura de Meloni (1975).

13. Cfr. Daniélou (1944:309-326). Puede verse una síntesis del tema de la epectasis y su aplicación a las homilías al Cantar en Reyes Gacitúa (2002:343-344).

14. Cfr. Reyes Gacitúa (2011:186189) donde estudia el problema del 'límite del conocimiento' en las homilías de Gregorio al Cantar. A su interesante exposición debemos añadir la consideración al contexto polémico anti-eunomiano del cual no habla la estudiosa chilena. 15. CF. Narvaja (2003:28-30). 


\section{Q Bibliografía}

\section{Fuentes}

» Origene, Gregorio di Nisssa. (2016). Sul cantico dei cantici, a cura di V. Limone e C. Moreschini. Milano: Bompiani.

"Origenes. (1920). Werke. 6. Homilien zum Hexateuch in Rufins Übersetzung, 1 (GSC 29) ed. W. A. Baehrens. Leipzig: Hinrichs'sche Buchhandlung.

» Orígenes. (2015). Sobre los principios, ed. Samuel Fernández (Fuentes patrísticas, 27). Madrid: Ciudad Nueva.

\section{Estudios}

» Canévet, M. (1983). Grégoire de Nysse et l'herméneutiqie biblique. Paris: Études Augustiniennes.

"Daniélou, J. (1944). Platonisme et théologie mystique. Essai sur la doctrine spirituelle de Saint Grégoire de Nysse. Paris: Aubier.

" Drecoll, V. (2018). "Spuren von Trinitätstheologie in den Hoheliedhomilien Gregors von Nyssa". En: Maspero, G.; Brugarolas, M.; Vigorelli, I. (eds.). Gregory of Nyssa: In Canticum Canticorum. Analytical and Supporting Studies. Proceedings of the 13th International Colloquium on Gregory of Nyssa (Rome, 17-20 September 2014) (SVigChr 150). Leiden - Boston: Brill, 180-199.

» Dünzl, F. (1993a). “Die Canticum-Exegese des Gregor von Nyssa und des Origenes im Vergleich", Jahrbuch für Antike und Christentum 36, 94-109.

»Dünzl, F. (1993b). Braut und Bräutigam. Die Auslegung des Canticum durch Gregor von Nyssa. Tübingen: Mohr.

"Escriban-Alberca, I. (1997). "Gegors von Nyssa in Cant.: Einige Beobachtungen zur mystischen Konstruktion biblischer Offenbarung", Studia Patristica 32, 108-120.

" Gargano, G.-I. (1981). La teoria di Gregorio di Nissa sul Cantico dei cantici. Roma: Pontificium Institutum Studiorum Orientalium.

» Laird, M. (2018). "Dew on the Locks of the Beloved: the In Canticum Canticorum on Faith and Knowledge". En: Maspero, G.; Brugarolas, M.; Vigorelli, I. (eds.). Gregory of Nyssa: In Canticum Canticorum. Analytical and Supporting Studies. Proceedings of the 13th International Colloquium on Gregory of Nyssa (Rome, 17-20 September 2014) (SVigChr 150). Leiden - Boston: Brill, 170-179.

" Meis, A. (1995). "Orígenes y Gregorio de Nisa, «In Canticum»". En: Dorival, G.; Le Boulluec, A. (eds.). Origeniana Sexta: Origène et la Bible / Origen and the Bible. Actes du Collloquium Origenianum Sextum, Chantilly, 30 août - 3 septembre 1993 (BEThL 118). Lovaina: Peeters, 599-616.

" Meloni, P. (1975). Il profumo dell'immortalità,. L'interpretazione patristica di Cantico 1,3. Roma: Studium. 
»Narvaja, J. (2003). Teología y Piedad en la obra de Eunomio de Cízico. Roma: Institutum Patristicum Augustinianum.

"Narvaja, J. (2018). "Describe tibi haec tripliciter..." Estudio sobre la recepción de los Padres de la Iglesia en el entorno de la abadía parisina de San Victo. Buenos Aires: Instituto Thomas Falkner

» Placida, R. (1997). "La presenza di Origene nelle Omelie sul Cantico dei cantici di Gregorio di Nissa”, Vetera Christianorum 34, 33-49.

» Reyes Gacitúa, E. (2002). "La reciprocidad. Algunas reflexines a partir de las Homilías I a IV de Gregorio de Nisa", Teología y Vida 43, 343-349.

» Reyes Gacitúa, E. (2006). “QQue me bese con los besos de su boca!”, Teología y Vida 47, 368-374.

» Reyes Gacitúa, E. (2007). "El perfume del Esposo. Según Gregorio de Nisa en el Comentario al Cantar de los Cantares", Teología y Vida 48, 207-214.

» Reyes Gacitúa, E. (2011). "«La voz del Amado». Palabras de promesa y realidad del entendimiento en el Com Cant de Gregorio de Nisa", Teología y Vida 52, 181-195.

» Simonetti, M. (1985). Lettera e/o allegoria. Un contributto alla storia dell'esegesi patristica. Roma: Institutum Patristicum Augustinianum.

» Simonetti, M. (2018). "Gregorio di Nissa interprete del Cantico dei Cantici". En: Maspero, G.; Brugarolas, M.; Vigorelli, I. (eds.). Gregory of Nyssa: In Canticum Canticorum. Analytical and Supporting Studies. Proceedings of the 13th International Colloquium on Gregory of Nyssa (Rome, 17-20 September 2014) (SVigChr 150). Leiden - Boston: Brill, 137-154.

» Vigorelli, I. (2014). "Desiderio e beatitudine: schesis nell'In Canticum canticorum di Gregorio di Nissa", Annales Theologici 28, 277-300. 
